\title{
Research on Dynamic and Complexity of Energy-Saving Investment about Multichannel and Multienergy Supply Chain
}

\author{
Fang $W u \mathbb{i}^{1,2}$ \\ ${ }^{1}$ College of Computer and Information Engineering, Tianjin Agricultural College, Tianjin 300384, China \\ ${ }^{2}$ Complex Dynamics Research Group, College of Management and Economics, Tianjin University, Tianjin, 300072, China
}

Correspondence should be addressed to Fang Wu; w-fang@hotmail.com

Received 7 May 2020; Accepted 27 June 2020; Published 15 July 2020

Academic Editor: Abdelalim A. Elsadany

Copyright (c) 2020 Fang Wu. This is an open access article distributed under the Creative Commons Attribution License, which permits unrestricted use, distribution, and reproduction in any medium, provided the original work is properly cited.

Considering the multienergy structure of the electricity market and supply-side competition reform in China, a dual-channel and multiproduct supply chain model is constructed. There are three players in the game model: new energy company and traditional energy company provide energy for the market and the State Grid at the same time. The State Grid is a retailer who buys electricity from two companies and supplies to the market after converting and transmitting the power. Three companies can invest in grid management for saving energy and reducing losses. The energy loss rate is an exponential function of line loss investment. Through the bifurcation graph, Lyapunov exponent, and the basin of parameter, the complex characteristics of the investment market are analyzed. It is interesting to find the Grazing-Hopf bifurcation which usually occurs in nonlinear circuits. The mixed expectation of bounded rationality and the naive expectation is conducive to suppressing the bifurcation and chaos of the market. When external shocks occur, the control model has good robustness.

\section{Introduction}

Supply-side reform has been continuously implemented in Chinese power industry [1]. The huge power market has gradually opened up, and customer can purchase electricity directly from the State Grid or power companies. Multienergy can be connected to the State Grid on a large scale. The electricity market shows a complex competition with multiple energy sources and multiple channels. Energy saving and lowcarbon development are urgent tasks for the world. For power enterprises, the loss in processes of transmission, substation, and distribution is the main power supply costs [2]. Reducing electricity loss is an important measure to ensure energy security and sustainable development.

Therefore, considering electricity reform of China, coexistence of macrocontrol and market competition, this study builds a dual-channel supply framework for multienergy supply. Based on the goals of saving energy strategy, a line loss investment model of multichannel supply chain is proposed, and the complex characteristics of investment market in line loss are analyzed.

\section{Related Research}

Considering economic practice, there are two types of research related to this article: electricity market reform and dual-channel supply chain.

2.1. Electricity Market Reform. The electricity market reform has always been a hot issue in the world. In regions with abundant energy supply, it was believed that encouraging competition was conducive to introducing new energy and lowering prices. In 1996, the European electricity market began to introduce liberalization and agreed that introducing competition could promote efficiency and reduce electricity price [3]. Zhang et al. [4] believed that electricity price reform and electricity trading were conducive to promoting the integration of renewable energy with the traditional power industry. In the Russian power industry, the combination of government regulation and appropriate market mechanisms was considered a suitable development strategy [5]. 
If energy was not available locally, some researchers thought that market-oriented reforms may be harmful. Australian scholars discovered [6] that power reform would bring hidden dangers to the power supply security. Woo et al. [7] found that competition in the electricity market could not bring stable prices and reliable services, and market-oriented reforms may bring great risks or even catastrophic consequences to the United Kingdom, Norway, Alberta (Canada), and California (United States).

Other scholars focused on how to introduce sustainable electricity through reform. Tian et al. [8] built a dynamic game model to analyze the promotion of natural gas reform. It was found that relaxing natural gas prices, levying carbon taxes, and choosing environmental subsidies could promote the market penetration of natural gas power. Taking Yunnan province of China as an example, Liu et al. [9] systematically analyzed a series of policies for introducing new energy.

At present, the reform of China's power market mainly focusses on two aspects: the introduction of new energy and trying to encourage competition. Those lead to multienergy and multichannel. This paper will build such a power supply structure model for analyzing this situation.

2.2. The Dual-Channel Supply Chain. Some scholars believed that the dual-channel supply chain structure could promote the green level of the product [10]. Rahmani et al. [11] built a dual-channel supply chain of green products by a mathematical method, solved the model by Invasive Weed Optimization algorithm (IWO), and verified the abovementioned result by Genetic algorithms considering the nonlinear characteristic. Rahmani and Yavari [12] built a dual-channel supply chain consisting of a green product manufacturer and a retailer, analyzed demand management in Stackelberg game, and found that reducing green costs can increase product's green level. Yang et al. [10] believed that environmental responsibility of green products led to dual channels choice and proposed a dual-channel structure strategy that considered behavioural characteristics.

Some scholars discovered that the dual-channel masterslave supply chain shows nonlinear dynamic characteristics and further explored its complex features [13, 14]. Zhang and Wang [13] analyzed the dynamic pricing strategy of the dual-channel supply chain, studied the impact of service value decisions on price, discussed the complex characteristics of the model, such as period and chaos, and further investigated the bullwhip effect. Lou and $\mathrm{Ma}$ [14] analyzed the dynamic characteristics of household appliances' supply chain considering energy saving and emission reduction. The optimal solutions of Nash equilibrium and Stackelberg were studied. The conditions for bifurcation and chaos were discussed, and a new phenomenon from cycle 2 to cycle 6 was discovered. However, according to the current competitive reform orientation of the Chinese power market, competitive games are more suitable for practice than master-slave games.

Therefore, based on the current power industry reform of China, this study will construct a dual-channel supply model with multienergy products, as Figure 1 shows, based

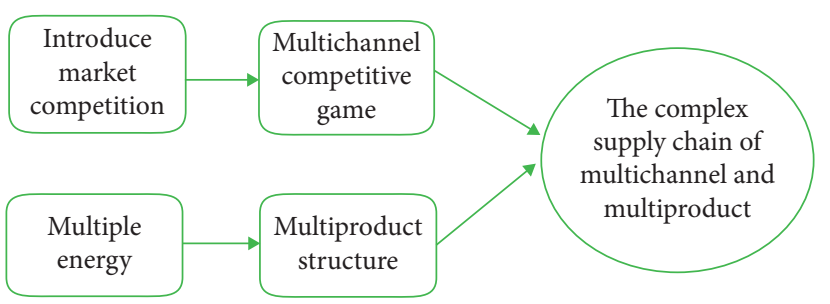

FIgURE 1: The structure of the supply chain.

on the goal of saving energy, building the line loss investment model, and analyzing its complex characteristics.

The structure of the article is arranged as follows. Section 3 includes the assumption, functions, and the model. Section 4 is the complexity simulation. Section 5 is the chaos control. Section 6 is the robustness analysis, and the last section is a conclusion.

\section{The Model}

\subsection{Assumptions}

(1) There are three types of enterprises in the Chinese electrical energy market: new energy enterprises, traditional enterprises based on coal burning, and the State Grid. Consumers can buy electricity from three companies.

(2) The State Grid established basic facilities for electric energy transmission and management. New energy company and traditional energy company supply power for the market at retail prices or for the State Grid at wholesale prices.

(3) Line loss occurs during energy transmission. In order to establish an energy-saving grid, new energy company, traditional energy company, and the State Grid are permitted to invest in line loss management.

The system structure diagram is shown in Figure 2.

In Figure 2, new energy companies, traditional energy companies, and the State Grid can provide electricity products to the market directly, and the market prices are $p_{1}, p_{2}$, and $p_{g}$, respectively. New energy company and traditional energy company provide electricity products for the State Grid, and the wholesale prices are $p_{s}$ and $p_{c}$, respectively. The State Grid purchases electric energy from two companies in proportion. The proportion from the traditional energy company is $\omega$, and the proportion from the new energy company is $1-\omega$. In order to promote the overall operating efficiency of the power grid, three companies can invest in grid management to reduce management line losses. Their investments are $x, y$, and $z$.

\subsection{Variables and Functions}

3.2.1. Line Loss Rate. Line loss occurs in energy transmission. The loss of electrical energy is divided into two parts $[15,16]$ : fixed line loss and management line loss. As long as the power transmission equipment is running, a fixed line loss will occur and is related to the power grid equipment, 


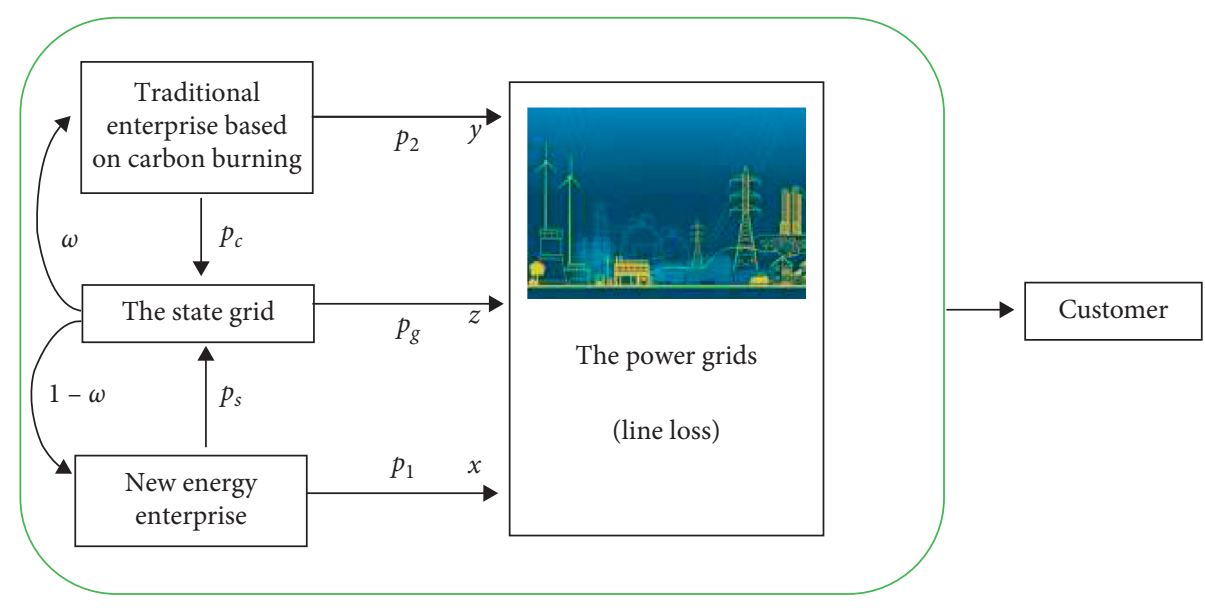

Figure 2: The model structure.

such as circuits, resistors, and network structure. It is not easy to change in the short term. Management line loss is related to electricity theft, management intensity, and the transmission paths planning. The increase in the management investment can reduce the management line loss. Some scholars have used an exponential function to build investment and decaying product models. Chung and Kwon [17] used an exponential investment model to study the impact of advertising investment on prices, and Guo and $\mathrm{Ma}$ [18] used an exponential model to study the output of decaying products. The exponential advertising investment model is introduced into the management line loss investment, and the decaying model was changed according to the composition of electric power line losses.

Three power companies invest in line loss management, and investments are represented by $x, y$, and $z$. The line loss investment function is

$$
L=(1-A)+A e^{-\sigma_{1} x-\sigma_{2} y-\sigma_{3} z-\sigma_{4} x y z} .
$$

The line loss composition is shown in Figure 3.

In equation (1) and Figure 3,1-A means the fixed line loss rate, which is related to the network architecture and hardware, and will not change in the short term; $A e^{-\sigma_{1} x-\sigma_{2} y-\sigma_{3} z-\sigma_{4} x y z}$ is the variable line loss rate which is related to the management intensity. $\sigma_{1} \sim \sigma_{4}$ are constants and represent degrees of influence.

\subsubsection{Investment Model for Line Loss Management}

The State Grid: $q_{g}$ is the output of the State Grid to the market. $d$ is the potential demand of electric energy in the market, $\theta_{1} d$ is the market's potential demand for the Station Grid, and $\theta_{1}$ is the proportional constant. $a, a_{1}$, and $a_{2}$ are influence parameters.

$$
q_{g}=\theta_{1} d-a p_{g}+a_{1} p_{1}+a_{2} p_{2} .
$$

The State Grid should carry out transmission, distribution, voltage transformation, and other operations for traditional energy and new energy before providing them to the market. It is a dual-product production

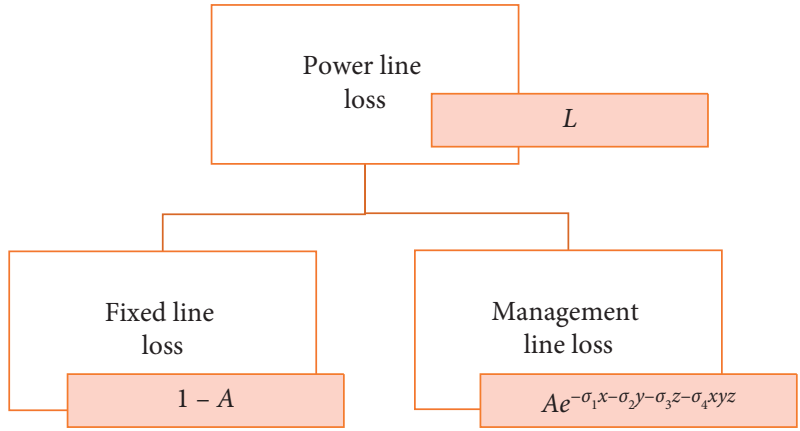

FIgURE 3: The line loss structure.

process that embodies the enterprise's flexible manufacturing $[19,20]$. The dual-product cost function is as follows:

$$
C_{g}=k+s+\left\{q_{g} w c_{r}+q_{g}(1-w)\left[c_{r}+r\left(1-d_{0}\right)\right]\right\} .
$$

The working cost of traditional carbon-fired electricity is $k$, and the marginal cost is $c_{r} . q_{g} w$ is the purchase amount from the traditional enterprise, and $q_{g}(1-w)$ is the purchase amount from the new energy enterprise. $w$ is the purchase share from the traditional enterprise by the State Grid.

The State Grid handles new energy through flexible manufacturing technology. The conversion cost of switching from one variety to another is $s$, and the marginal cost of processing new energy is $c_{r}+r\left(1-d_{0}\right)$.

$r\left(1-d_{0}\right)$ is the increase in the cost of changing. The greater the gap between the processing of traditional energy and new energy, the greater the cost of changing.

The profit function of the State Grid is

$\prod_{g}=q_{g} p_{g} L-p_{s} q_{g}(1-w)-p_{c} q_{g} w-c_{g} q_{g}-z$. 
New energy enterprise: the power provided by new energy companies for the market is $q_{1}$, the total output of new energy enterprise is $q_{s} . c_{1}$ is the marginal cost, and the profit function is $\prod_{s}$.

$$
\begin{aligned}
q_{1} & =\left(1-\theta_{1}\right)\left(1-\theta_{2}\right) d-a p_{1}+a_{1} p_{g}+a_{2} p_{2}, \\
q_{s} & =q_{1}+q_{g}(1-w), \\
\prod_{s} & =p_{1} q_{1} L+p_{s} q_{g}(1-w)-c_{1} q_{s}-x .
\end{aligned}
$$

Traditional power enterprises based on carbon burning: the power provided by the traditional energy company for the market is $q_{2}$, and the total output of traditional enterprise is $q_{c} . c_{2}$ is the marginal cost, and the profit function is $\prod_{c}$.

$$
\begin{aligned}
q_{2} & =\left(1-\theta_{1}\right) \theta_{2} d-a p_{2}+a_{1} p_{1}+a_{2} p_{g}, \\
q_{c} & =q_{2}+q_{g} w, \\
\prod_{c} & =p_{2} q_{2} L+p_{c} q_{g} w-c_{2} q_{c}-y .
\end{aligned}
$$

$\theta_{1}$ and $\theta_{2}$ are the proportional coefficients about the potential demand.

3.3. The Model. Assuming that line loss investments of three companies follow the rule of bounded rational expectation, that is, adjusting the investment of the current period according to the marginal profit of the previous period, the discrete dynamic equations of the system can be obtained as follows:

$$
\left\{\begin{array}{l}
x^{\prime}=x+\varepsilon x \frac{\partial \prod_{s}}{\partial x}, \\
y^{\prime}=y+\phi y \frac{\partial \prod_{c}}{\partial y} \\
z^{\prime}=z+\eta z \frac{\partial \prod_{g}}{\partial z},
\end{array}\right.
$$

' means unite time advancement of the variable. Namely,

$$
\left\{\begin{array}{l}
x^{\prime}=x+\varepsilon x\left\{A p_{1}\left(\sigma_{1}+y z \sigma_{4}\right)\left[a_{2} p_{2}-a p_{1}+a_{1} p_{g}+d\left(\theta_{1}-1\right)\left(\theta_{2}-1\right)\right] e^{-x \sigma_{1}-y \sigma_{2}-z \sigma_{3}-x y z \sigma_{4}}+1\right\} \\
Y^{\prime}=y+\phi y\left\{A p_{2}\left(\sigma_{2}+x z \sigma_{4}\right)\left[a p_{2}-a_{1} p_{1}-a_{2} p_{g}+d \theta_{2}\left(\theta_{1}-1\right)\right] e^{-x \sigma_{1}-y \sigma_{2}-z \sigma_{3}-x y z \sigma_{4}}-1\right\} \\
z^{\prime}=z+\eta z\left\{A p_{g}\left(\sigma_{3}+x y \sigma_{4}\right)\left(a_{1} p_{1}+a_{2} p_{2}-a p_{g}+d \theta_{1}\right) e^{-x \sigma_{1}-y \sigma_{2}-z \sigma_{3}-x y z \sigma_{4}}+1\right\}
\end{array}\right.
$$

Let

$$
\left\{\begin{array} { l } 
{ x ^ { \prime } = x , } \\
{ y ^ { \prime } = y , } \\
{ z ^ { \prime } = z . }
\end{array} \quad \left\{\begin{array}{l}
\frac{\partial \prod_{s}}{\partial x}=0 \\
\frac{\partial \prod_{c}}{\partial y}=0 \\
\frac{\partial \prod_{g}}{\partial z}=0 .
\end{array}\right.\right.
$$

Namely,

The Nash equilibrium point $\left(x^{*}, y^{*}, z^{*}\right)$ can be obtained as follows:

$$
\left\{\begin{array}{l}
x^{*}=-\left\{\ln \left\{-\frac{1}{A p_{1}\left(\sigma_{1}+y z \sigma_{4}\right)\left[a_{2} p_{2}-a p_{1}+a_{1} p_{g}+d\left(\theta_{1}-1\right)\left(\theta_{2}-1\right)\right]}\right\}+y \sigma_{2}+z \sigma_{3}\right\}\left(\frac{1}{\sigma_{1}+y z \sigma_{4}}\right), \\
y^{*}=-\frac{1}{\sigma_{2}+x z \sigma_{4}}\left\{\ln \left[\frac{1}{A p_{2}\left(\sigma_{2}+x z \sigma_{4}\right)\left(a p_{2}-a_{1} p_{1}-a_{2} p_{g}+d \theta_{2} \theta_{1}-d \theta_{2}\right)}\right]+x \sigma_{1}+z \sigma_{3}+x z \sigma_{4}\right\} \\
z^{*}=-\frac{1}{\sigma_{3}+x y \sigma_{4}}\left\{\ln \left[-\frac{1}{A p_{g}\left(\sigma_{3}+x y \sigma_{4}\right)\left(a_{1} p_{1}+a_{2} p_{2}-a p_{g}+d \theta_{1}\right)}\right]+x \sigma_{1}+y \sigma_{2}\right\} .
\end{array}\right.
$$

In existing research [21, 22], according to the jury [23] conditions, the stability of the system equilibrium point can be obtained through calculating the Jacobian matrix of the model and its eigenvalues. But in this model, the complex exponential line loss function and multiproduct structure make the calculation amount huge, and the results cannot be 


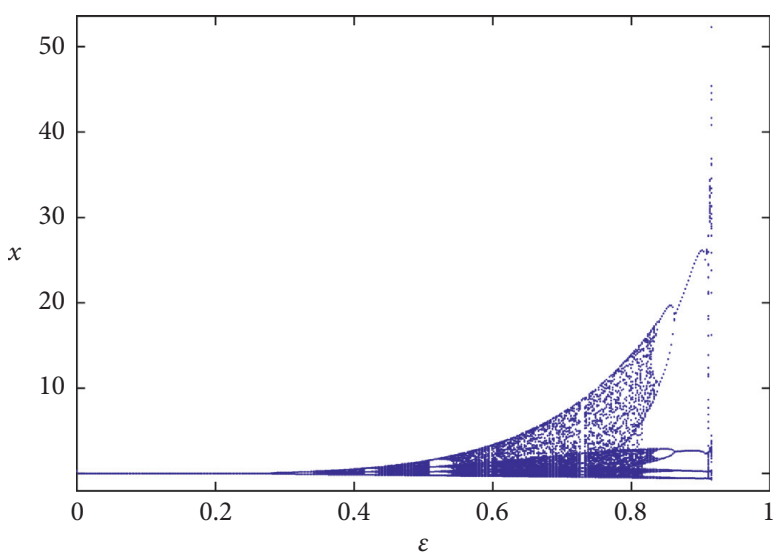

(a)

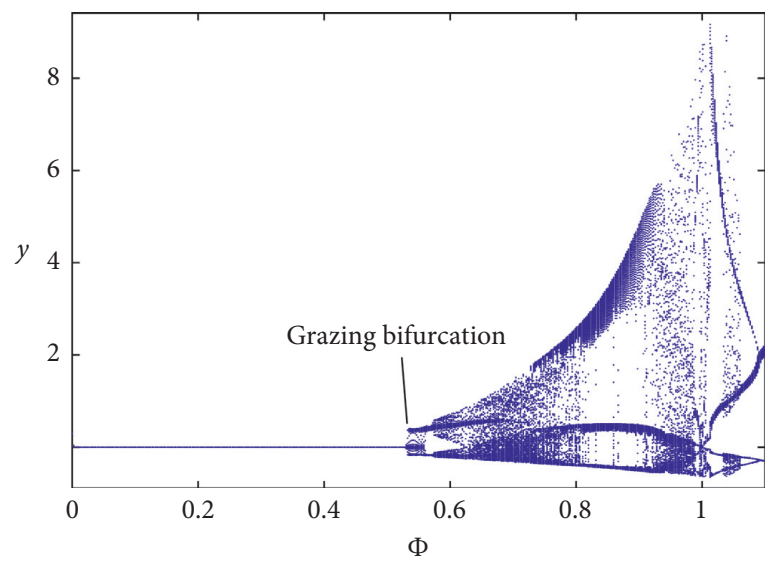

(c)

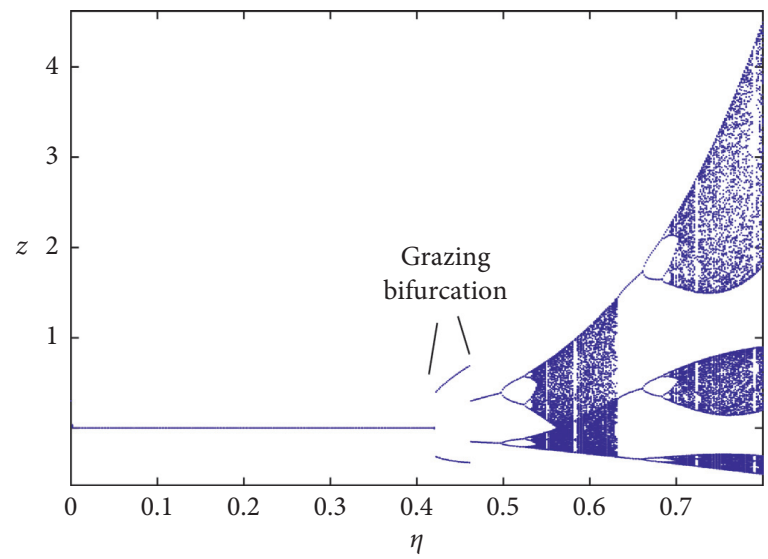

(e)

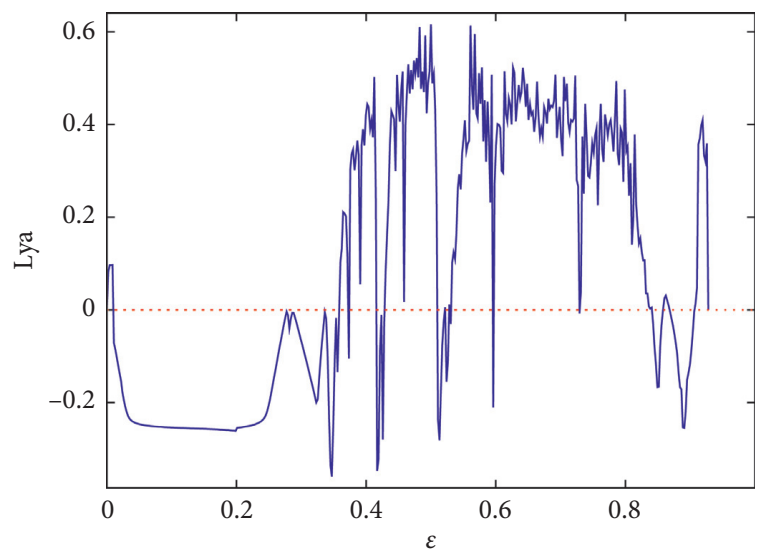

(b)

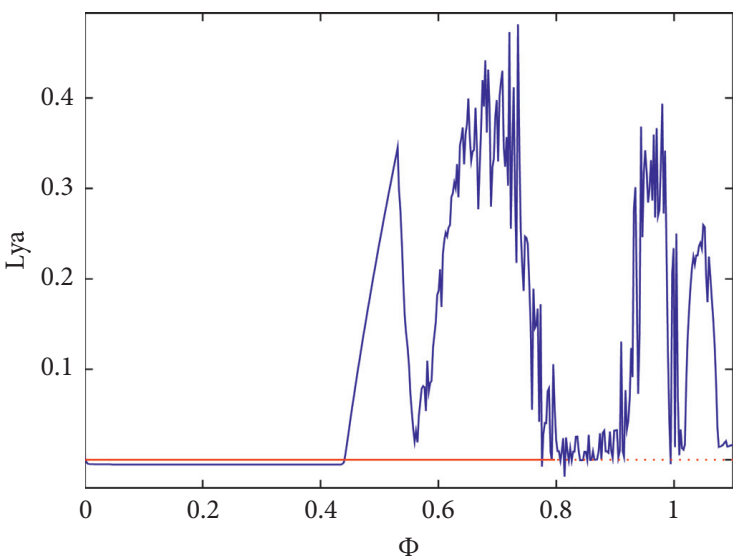

(d)

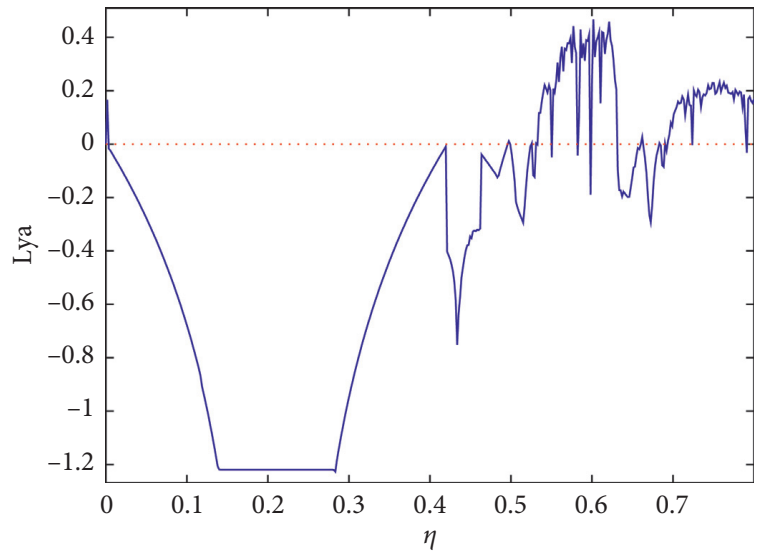

(f)

Figure 4: Bifurcation diagrams and Lyapunov exponents. (a) $\eta=0.3, \varphi=0.3$. (b) $\eta=0.3, \varphi=0.3$. (c) $\varepsilon=0.3, \eta=0.3$. (d) $\varepsilon=0.3, \eta=0.3$. (e) $\varepsilon=0.35, \varphi=0.35$. (f) $\varepsilon=0.35, \varphi=0.35$.

expressed by the mathematical analysis method. Therefore, this study turns to the numerical simulation to explore the period, chaos, and stability characteristics.

\section{The Simulation}

4.1. The Bifurcation and Lyapunov. In order to explore the complex characteristics of the model through numerical simulation, parameter values are set as follows:

$$
\begin{aligned}
c_{1} & =0.2 ; c_{2}=0.3 ; \theta_{1}=0.8 ; \theta_{2}=0.9 ; \\
A & =0.7 ; \sigma_{1}=3 ; \sigma_{2}=2 ; \sigma_{3}=3 ; \sigma_{4}=2 ; s=0.3 ; a=1 ; \\
a_{1} & =1 ; a_{2}=1 ; w=0.5 ; d_{0}=0.1 ; \\
r & =0.5 ; k=0.5 ; d=1.2 ; c_{r}=0.1 .
\end{aligned}
$$

Figure 4 shows the bifurcation diagrams and Lyapunov exponents with changing $\varepsilon, \varphi$, and $\eta$. In (a) and (b), the model enters chaos through Hopf bifurcation. (c) and (e) 


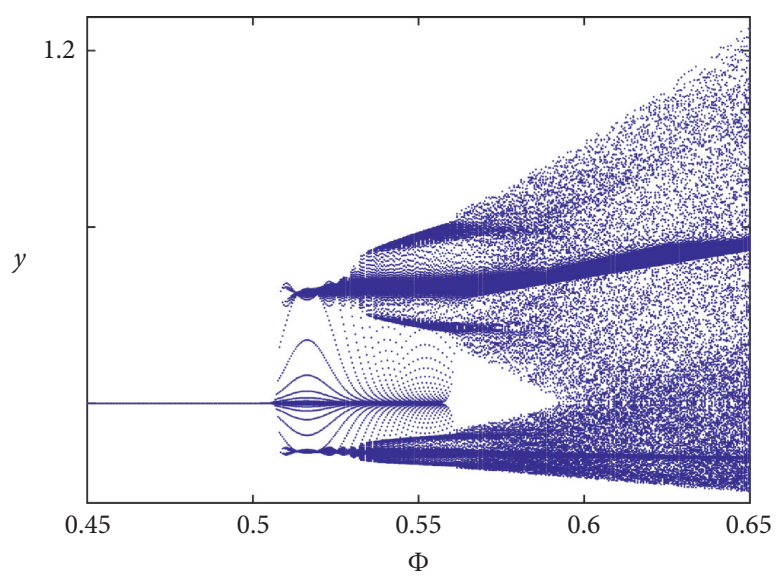

Figure 5: Detailed view of the grazing bifurcation.

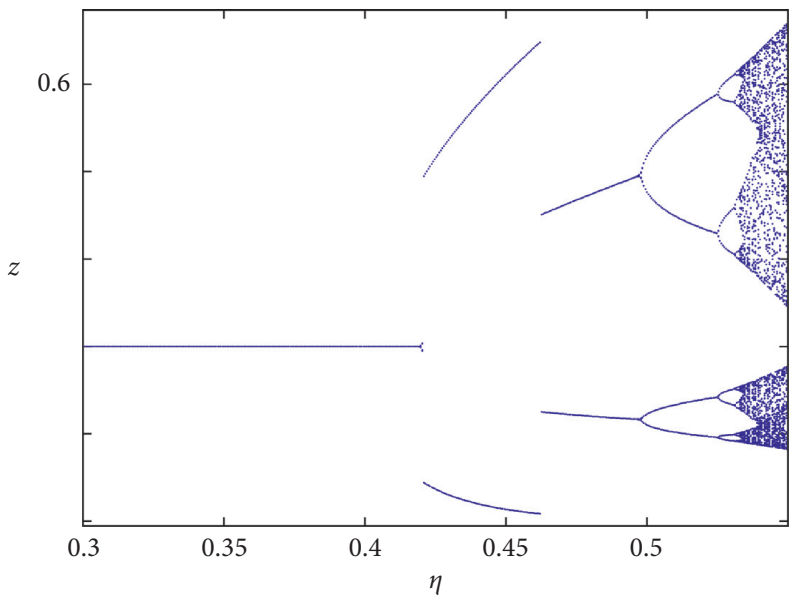

Figure 6: The Grazing-Hopf bifurcation.

show mutations: Grazing bifurcations appear, and it often occurred in nonlinear circuit theory [24]. As in (c), the investment of new energy enterprise enters chaos after Grazing bifurcation. Figure 5 is a detailed view of the process. As in (e), the system enters the two-cycle orbit from the steady state through the Grazing bifurcation mutation. In the two-period orbit, the Grazing bifurcation mutation occurs again, and then enters chaos through the Hopf bifurcation, as Figure 6 detailed.

4.2. The Basin of Parameter. In this section, basins of parameter in Figure 7 show the model's complex character. Orange represents stable equilibrium, green represents the two-period orbit, brown represents three-period, dark green represents the 4-period orbit, blue means the 6-period orbit, and magenta represents the 8-period orbit, white represents nonconvergence and yellow-green represent divergence.

\section{Chaos Control Based on Mixed Expectation}

In the existing differential economic system, there are three types of expectation rules $[25,26,27]$ : the bounded rational expectation, the naive expectation, and the adaptive expectation. The bounded rational expectation has the strongest complex characteristics, followed by adaptive expectations, and the last is naive expectations which do not have complex characteristics when used alone. This section will study the impact of the mixed expectation rule (the combination of the bounded rationality and naive expectation) on the complexity of the economic system.

The mixed expectation model is as follows:

$$
\left\{\begin{array}{l}
x=\left(1-\operatorname{Con}_{1}\right)\left\{x+\varepsilon x\left\{A p_{1}\left(\sigma_{1}+y z \sigma_{4}\right)\left[a_{2} p_{2}-a p_{1}+a_{1} p_{g}+d\left(\theta_{1}-1\right)\left(\theta_{2}-1\right)\right] e^{-x \sigma_{1}-y \sigma_{2}-z \sigma_{3}-x y z \sigma_{4}}+1\right\}\right\}+\operatorname{Con}_{1} x \\
y=\left(1-\operatorname{Con}_{2}\right)\left\{y+\phi y\left\{A p_{2}\left(\sigma_{2}+x z \sigma_{4}\right)\left[a p_{2}-a_{1} p_{1}-a_{2} p_{g}+d \theta_{2}\left(\theta_{1}-1\right)\right] e^{-x \sigma_{1}-y \sigma_{2}-z \sigma_{3}-x y z \sigma_{4}}-1\right\}\right\}+\operatorname{Con}_{2} y \\
z=\left(1-\operatorname{Con}_{3}\right)\left\{z+\eta z\left\{A p_{g}\left(\sigma_{3}+x y \sigma_{4}\right)\left(a_{1} p_{1}+a_{2} p_{2}-a p_{g}+d \theta_{1}\right) e^{-x \sigma_{1}-y \sigma_{2}-z \sigma_{3}-x y z \sigma_{4}}+1\right\}\right\}+\operatorname{Con}_{3} y
\end{array}\right.
$$




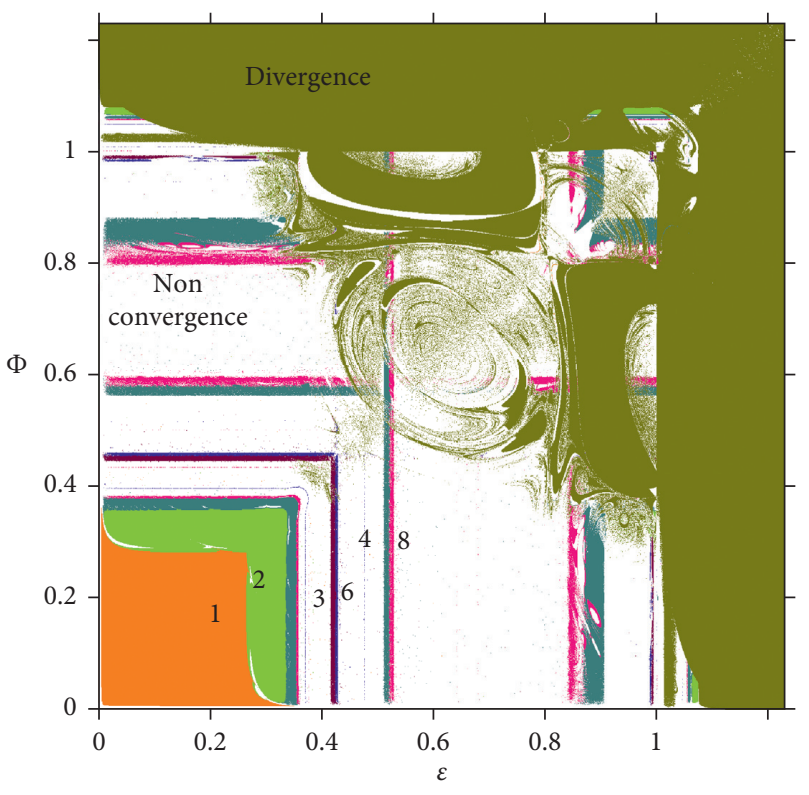

(a)

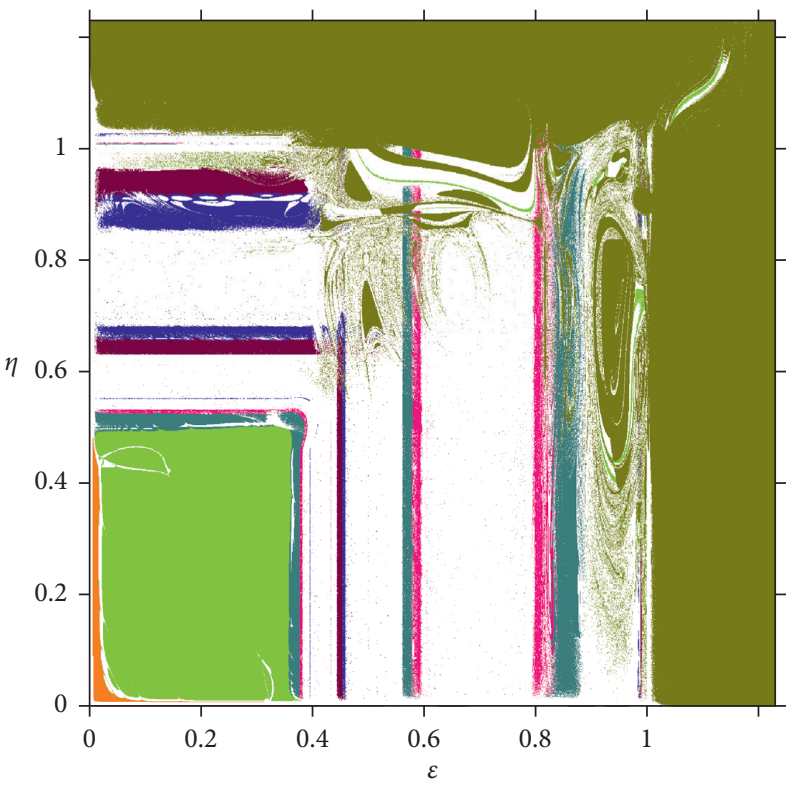

(b)

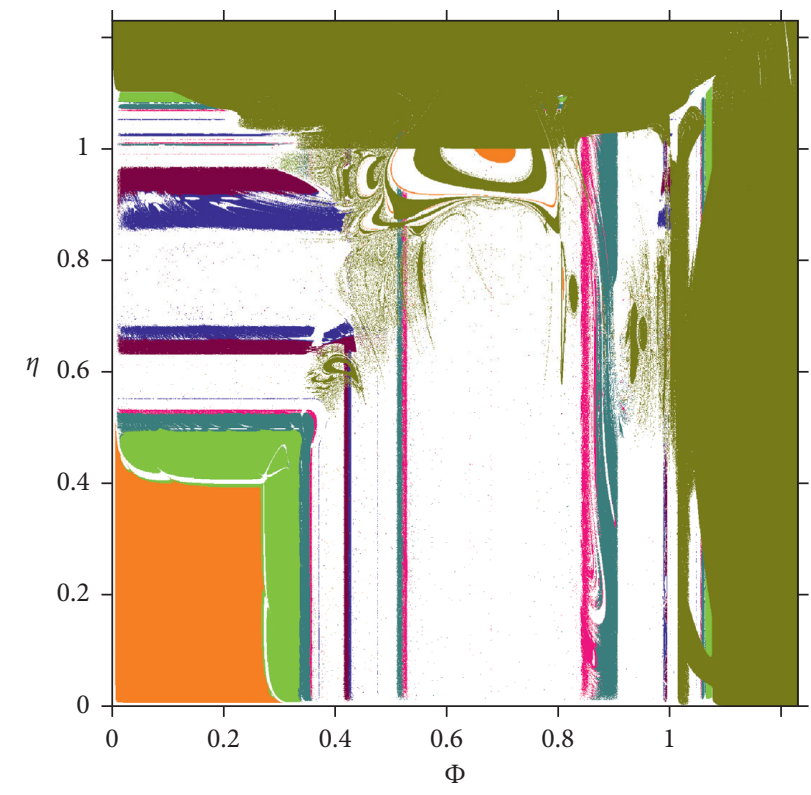

(c)

Figure 7: The basin of parameter. (a) The basin of $\varepsilon$ and $\phi$. (b) The basin of $\varepsilon$ and $\eta$. (c) The basin of $\phi$ and $\eta$.

$\mathrm{Con}_{i}(i=1,2,3)$ is the weight for choosing the naive expectation, and $1-\mathrm{Con}_{i}$ is the weight for choosing the bounded rational expectation. For research convenience, let $\mathrm{Con}_{1}=\mathrm{Con}_{2}=\mathrm{Con}_{3}=$ Con. Looking at the parameter base diagram in Figure 8, we can find that even if the investment adjustment speed parameter increases, the system's stable region is still gradually expanding with increasing Con.

\section{Robustness Analysis}

External shocks such as natural disasters, epidemic outbreaks, and financial crises will directly affect power grid investment. When the shock occurs, the investment is interrupted. When the emergency disappears, the investment rebounds. The drastic changes of investment shock the stability of the market. In this section, we study the 


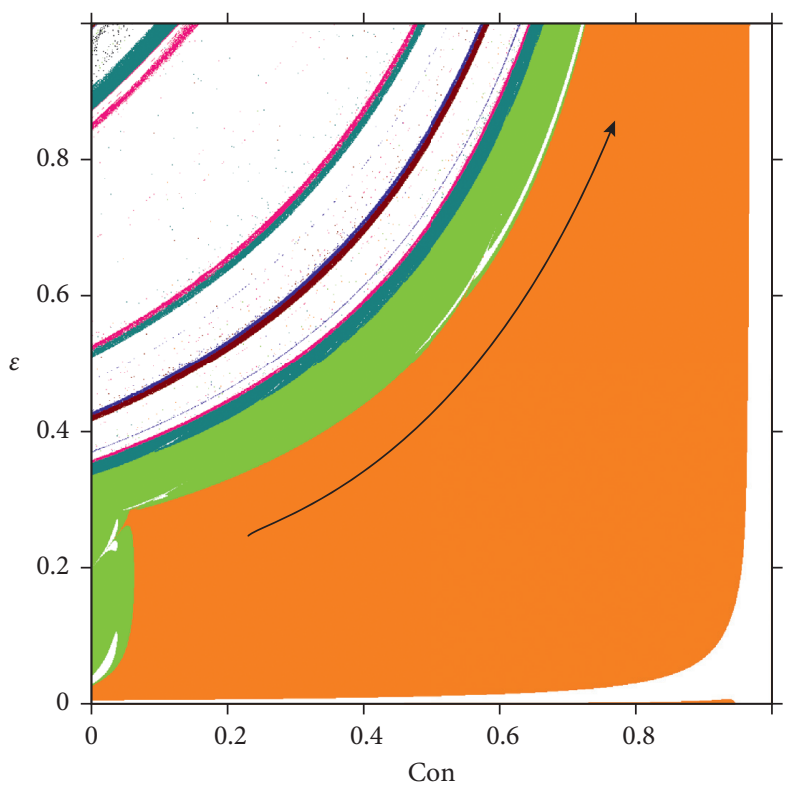

(a)

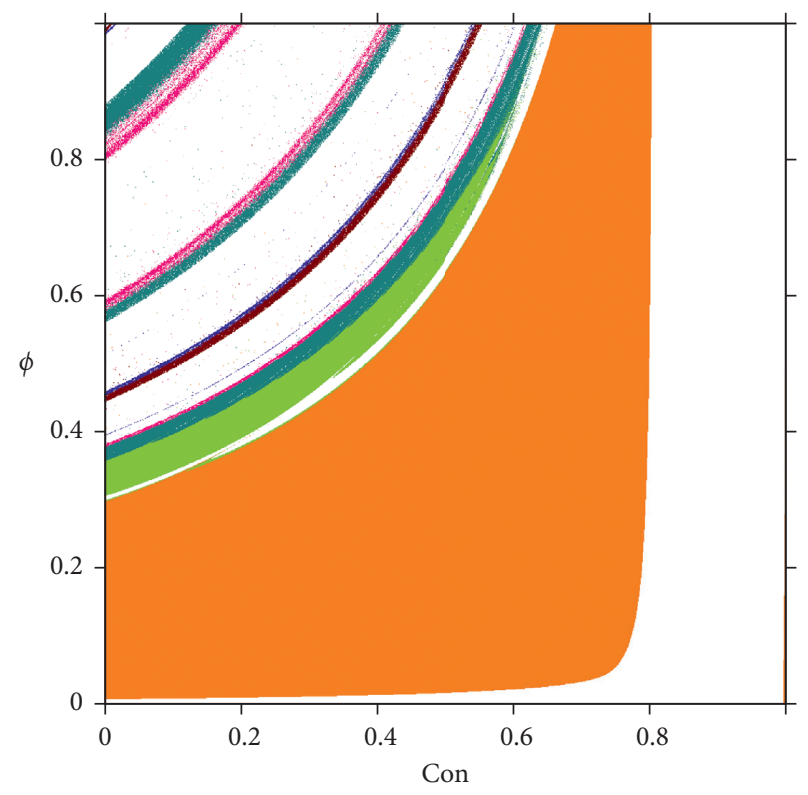

(b)

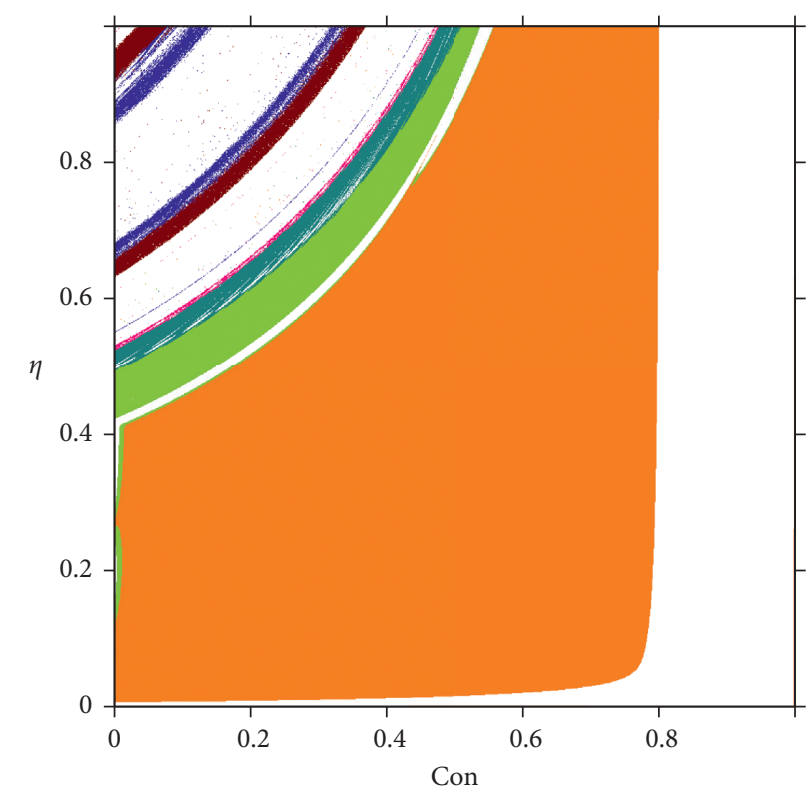

(c)

Figure 8: The basin of parameter under control. (a) The basin of Con and $\varepsilon$. (b) The basin of Con and $\phi$. (c) The basin of Con and $\eta$.

robustness of the mixed expectation control method under severe fluctuations in investment.

In Figure 9(a), there is no control $(\eta=0.3)$. As shown in Figure 9(b), the investment rate $\eta$ suddenly increases to 0.9 from 0.3 , the steady state disappears, and the cycle bifurcation and chaos interlace occur. After adopting the mixed expectation control strategy, when the control coefficient is 0.6 , the same external mutation occurs, and the parameter base diagram is shown in (c): equilibrium appears. If the control coefficient is increased to 0.9 , even if the outside world suddenly changes, the system will be in Nash equilibrium with great probability, as (d) shows. 


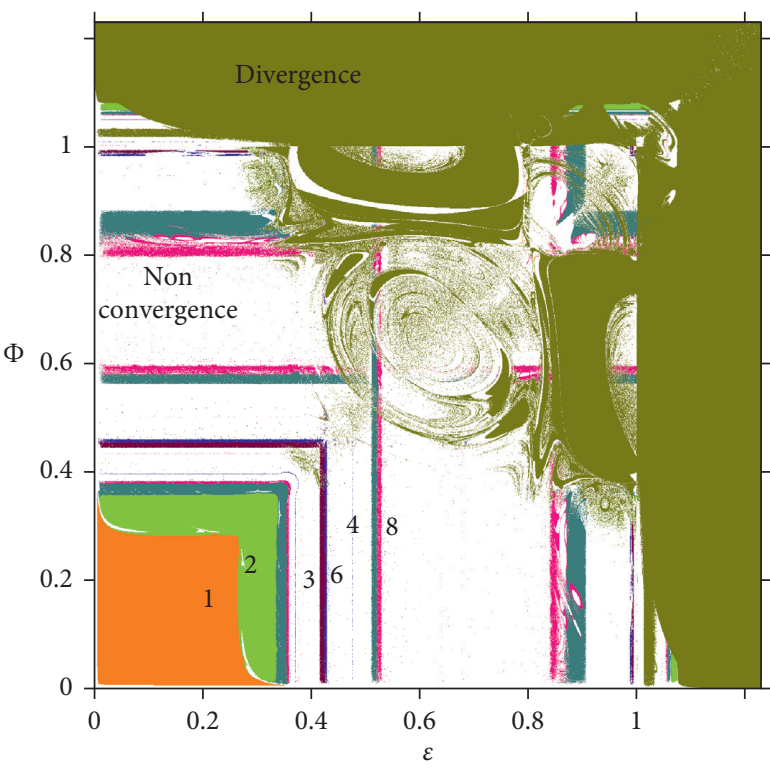

(a)

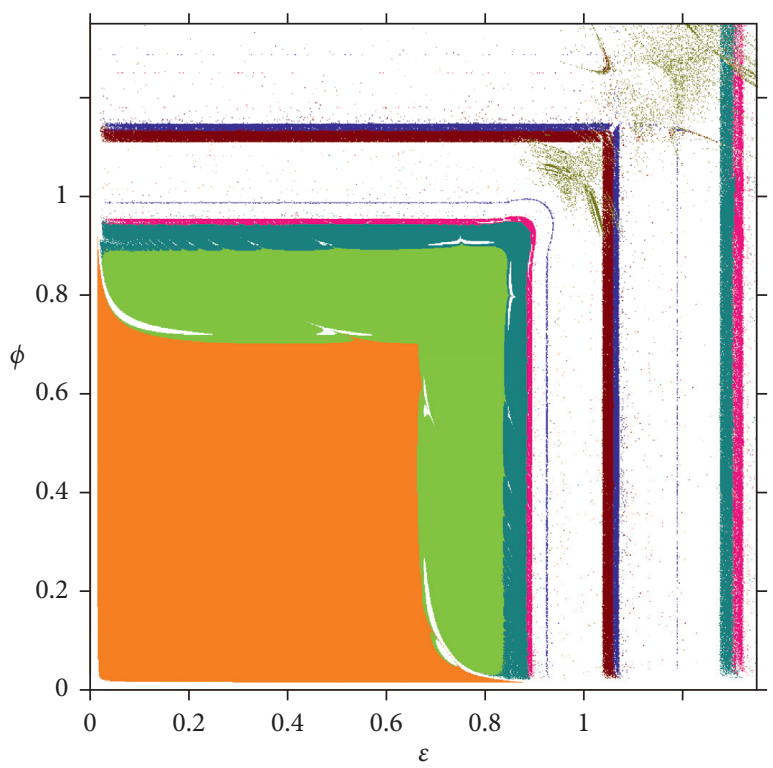

(c)

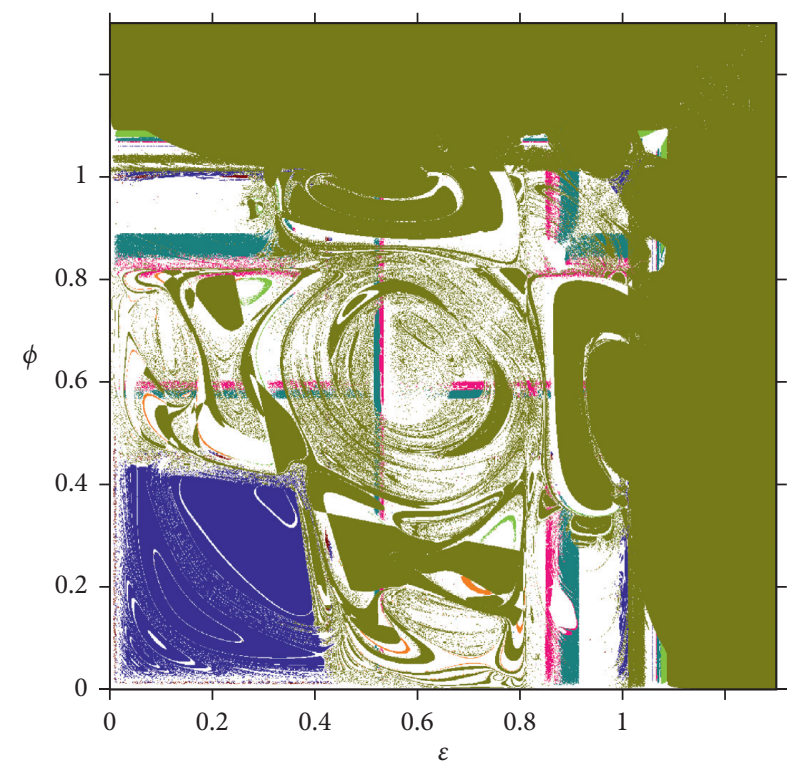

(b)

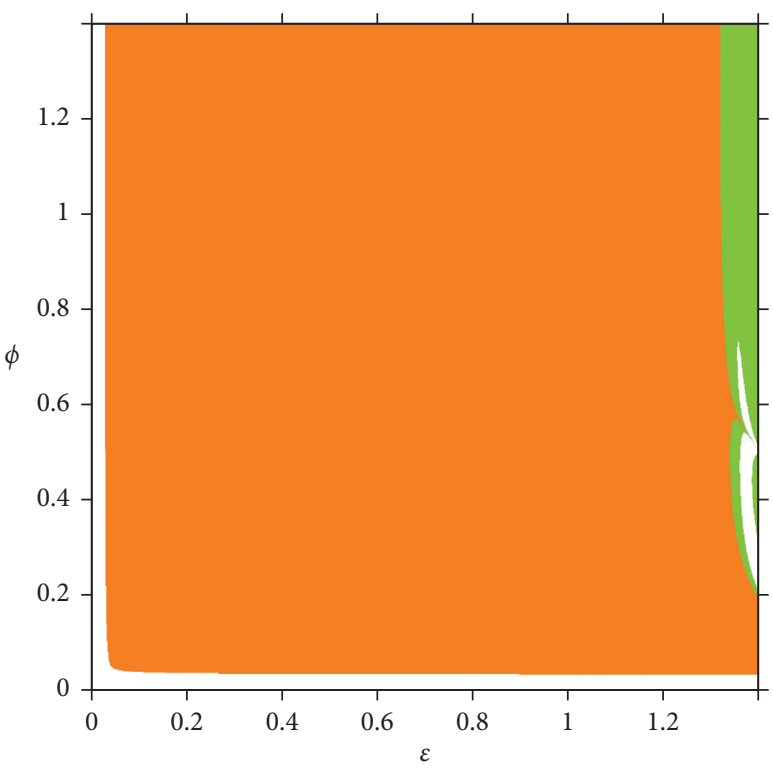

(d)

Figure 9: The parameter basin of robustness. (a) Con $=0, \eta=0.3$. (b) $\eta=0.9=0.9$. (c) $\eta=0.9=$, Con $=0.6$. (d) $\eta=0.9$, Con $=0.8$.

\section{Conclusions}

For supply-side reform of China, multiple energy production companies enter the market, and the competition between multienergy enterprises and the State Grid appears. At this time, the State Grid deals with multiple energy sources from power enterprises and retails them. Based on the abovementioned realities, a dual-channel and multiproduct supply chain model is constructed, in which energy companies conduct dual-channel sales and the State Grid corporation processes multiple power. For saving energy, all companies are permitted to invest in reducing line loss, and the energy loss rate is an exponential function of investments. The bifurcation graph, Lyapunov exponent, parameter basin, and other techniques are used to analyze the complex characteristics of the system. In this economic model, besides the double-cycle bifurcation, a Grazing-Hopf bifurcation is found, which usually occurs in nonlinear circuits. The study finds that the mixed strategy that is combined by bounded rationality and naive expectation can suppress bifurcation and chaos. Also, the parameter basin technique is used to analyze the robustness of the control method. This paper enriches the issue about complex dynamics of economics. 


\section{Data Availability}

The data used to support the findings of this study are included within the article.

\section{Conflicts of Interest}

The author declares that there are no conflicts of interest regarding the publication of this paper.

\section{Acknowledgments}

This research was supported by the Philosophy and Social Science Planning Project of Tianjin, China (No. TJGL19027).

\section{References}

[1] Z. Yu, "Beyond the state market dichotomy: institutional innovations in China's electricity industry reform," Journal of Environmental Management, vol. 264, no. 15, Article ID 110306, 2020

[2] M. A. Sayed and T. Takeshita, "Line loss minimization in isolated substations and multiple loop distribution systems using the UPFC," IEEE Transactions on Power Electronics, vol. 29, no. 11, pp. 5813-5822, 2014.

[3] A. Kaller, S. Bielen, and W. Marneffe, "The impact of regulatory quality and corruption on residential electricity prices in the context of electricity market reforms," Energy Policy, vol. 123, pp. 514-524, 2018.

[4] S. Zhang, P. Andrews-Speed, and S. Li, "To what extent will China's ongoing electricity market reforms assist the integration of renewable energy?" Energy Policy, vol. 114, pp. 165-172, 2018.

[5] K. Letova, R. Yao, M. Davidson, and E. Afanasyeva, "A review of electricity markets and reforms in Russia," Utilities Policy, vol. 53, pp. 84-93, 2018.

[6] M. Abbott and B. Cohen, "Finding a way forward: policy reform of the Australian national electricity market," The Electricity Journal, vol. 31, no. 6, pp. 65-72, 2018.

[7] C.-K. Woo, D. Lloyd, and A. Tishler, "Electricity market reform failures: UK, Norway, Alberta and California," Energy Policy, vol. 31, no. 11, pp. 1103-1115, 2003.

[8] R. Tian, Q. Zhang, G. Wang et al., "Study on the promotion of natural gas-fired electricity with energy market reform in China using a dynamic game-theoretic model," Applied Energy, vol. 185, pp. 1832-1839, 2017.

[9] S. Liu, Q. Yang, H. Cai et al., "Market reform of Yunnan electricity in southwestern China: practice challenges and implications," Renewable and Sustainable Energy Reviews, vol. 113, Article ID 109265, 2019.

[10] D. Yang, T. Xiao, and J. Huang, "Dual-channel structure choice of an environmental responsibility supply chain with green investment," Journal of Cleaner Production, vol. 210, pp. 134-145, 2019.

[11] D. Rahmani, M. Q. Hasan Abadi, and S. J. Hosseininezhad, "Joint decision on product greenness strategies and pricing in a dual-channel supply chain: a robust possibilistic approach," Journal of Cleaner Production, vol. 256, Article ID 120437, 2020.

[12] K. Rahmani and M. Yavari, "Pricing policies for a dualchannel green supply chain under demand disruptions,"
Computers \& Industrial Engineering, vol. 127, pp. 493-510, 2019.

[13] F. Zhang and C. Wang, "Dynamic pricing strategy and coordination in a dual-channel supply chain considering service value," Applied Mathematical Modelling, vol. 54, pp. 722-742, 2018.

[14] W. Lou and J. Ma, "Complexity of sales effort and carbon emission reduction effort in a two-parallel household appliance supply chain model," Applied Mathematical Modelling, vol. 64 , pp. $398-425,2018$.

[15] P. Raj and S. Senthilkumar, "Optimization of distributed generation capacity for line loss reduction and voltage profile improvement using PSO," Journal of Electrical Engineering, vol. 2, 2018.

[16] N. Inayoshi, M. A. Sayed, T. Takeshita, N. Izuhara, and F. Ueda, "Construction method of loop distribution system for line loss minimization," IEEJ Transactions on Power \& Energy, vol. 128, no. 6, pp. 893-894, 2018.

[17] S. H. Chung and C. Kwon, "Integrated supply chain management for perishable products: dynamics and oligopolistic competition perspectives with application to pharmaceuticals," International Journal of Production Economics, vol. 179, pp. 117-129, 2016.

[18] Z. Guo and J. Ma, "Dynamics and implications on a cooperative advertising model in the supply chain," Communications in Nonlinear Science and Numerical Simulation, vol. 64, pp. 198-212, 2018.

[19] D. C. Chisholm and G. Norman, "Market access and competition in product lines," International Journal of Industrial Organization, vol. 30, no. 5, pp. 429-435, 2012.

[20] A. Garcia-Gallego and N. Georgantzis, "Multiproduct activity in an experimental differentiated oligopoly," International Journal of Industrial Organization, vol. 19, no. 3-4, pp. 493518, 2001.

[21] A. A. Elsadany and A. M. Awad, "Dynamics and chaos control of a duopolistic Bertrand competitions under environmental taxes," Annals of Operations Research, vol. 274, no. 1-2, pp. 211-240, 2019.

[22] F. Wu and J. Ma, "The equilibrium, complexity analysis and control in epiphytic supply chain with product horizontal diversification," Nonlinear Dynamics, vol. 93, no. 4, pp. 2145-2158, 2018.

[23] L. E. Eeshet, Mathematical Models in Biology, Random House, New York, NY, USA, 1992.

[24] S. Yin, G. Wen, H. Xu, and X. Wu, "Higher order zero time discontinuity mapping for analysis of degenerate grazing bifurcations of impacting oscillators," Journal of Sound and Vibration, vol. 437, pp. 209-222, 2018.

[25] C. Hommes, Behavioral Rationality and Heterogeneous Expectations in Complex Economic Systems, Cambridge University Press, Cambridge, United Kingdom, 2013.

[26] B. Xin, J. Ma, and Q. Gao, "Complex dynamics of an adnascent-type game model," Discrete Dynamics in Nature and Society, vol. 2008, Article ID 467972, pp. 1-12, 2008.

[27] J. Ma, W. Lou, and Y. Tian, "Bullwhip effect and complexity analysis in a multi-channel supply chain considering price game with discount sensitivity," International Journal of Production Research, vol. 57, no. 17, pp. 5432-5452, 2019. 